\title{
Intravenous and subsequent long-term oral tranexamic acid in enhanced-recovery primary total knee arthroplasty without the application of a tourniquet: a randomized placebo-controlled trial
}

Hao-Yang Wang ${ }^{1 \dagger}$, Liu Wang ${ }^{2,3+}$, Ze-Yu Luo ${ }^{1}$, Duan Wang ${ }^{1}$, Xin Tang ${ }^{1 *}$, Zong-Ke Zhou $^{1 *}$ (D) and Fu-Xing Pei ${ }^{1}$

\begin{abstract}
Background: To assess the efficacy and safety of intravenous and subsequent long-term oral tranexamic acid (TXA) following total knee arthroplasty (TKA) without a tourniquet.

Methods: In this double-blinded trial, 118 patients undergoing primary TKA were randomized into two groups: the patients in group A received intravenous TXA at 20-mg/ $\mathrm{kg} 10 \mathrm{~min}$ before the surgery and $3 \mathrm{~h}$ postoperatively, and then oral $1 \mathrm{~g}$ TXA from postoperative day (POD) 1 to POD 14, and the patients in group B received intravenous TXA at 20-mg/kg $10 \mathrm{~min}$ before surgery and $3 \mathrm{~h}$ postoperatively, and then oral $1 \mathrm{~g}$ placebo from postoperative day (POD) 1 to POD 14. The primary outcome was total blood loss. Secondary outcomes included ecchymosis area and morbidity, postoperative transfusion, postoperative laboratory values, postoperative knee function and length of hospital stay. Complications, and patient satisfaction were also recorded.

Results: The mean total blood loss was lower in Group A than in Group B $(671.7 \mathrm{ml}$ vs $915.8 \mathrm{ml}, P=0.001)$. There was no significant difference in the transfusion rate between the two groups. Group A had a higher hemoglobin than Group B on POD 3 (106.0 g/L vs $99.7 \mathrm{~g} / \mathrm{L}, P=0.001)$. However, no significant difference was found for $\mathrm{Hb}$ or hematocrit on POD 1 or POD 14 between the two groups. Patients in Group A had less ecchymosis morbidity (7 vs $38, P=0.001$ ), smaller ecchymosis area (1.6 vs 3.0, $P=0.001$ ) than Group B. The blood coagulation level as measured by fibrinolysis (D-Dimer) was lower in Group A than in Group B on POD 1 and POD 3 (4.6 mg/L vs. $8.4 \mathrm{mg} / \mathrm{L}$, respectively, $P=0.001 ; 1.5 \mathrm{mg} / \mathrm{L}$ vs. $3.3 \mathrm{mg} / \mathrm{L}$, respectively, $P=0.001$. However, there was no significant difference on $P O D 14$, and the fibrin degradation products showed the same trend. Patients in Group A had less swelling than those in Group B on POD 3 and POD 14. The circumference of the knee was $43.1 \mathrm{~cm}$ vs. $46.1 \mathrm{~cm}$ (POD 3, $P=0.001$ ) and $41.4 \mathrm{~cm}$ vs. $44.9 \mathrm{~cm}$ (POD 14, $P=0.001)$ in Group A vs Group B, respectively. Nevertheless, the circumference of the knee in the two groups was similar on POD 1 and POD $3 \mathrm{M}$. No significant differences were identified in knee function, pain score, or hospital stay. No significant differences were identified in thromboembolic complications, infection, hematoma, wound healing and patients satisfaction between the two groups.

(Continued on next page)
\end{abstract}

*Correspondence: tangxin9388@163.com; zongkehx@163.com

†Hao-Yang Wang and Liu Wang contributed equally to this work.

'Department of Orthopedics, West China Hospital/West China School of

Medicine, Sichuan University, 37\# Wuhou Guoxue road, Chengdu 610041,

People's Republic of China

Full list of author information is available at the end of the article

(c) The Author(s). 2019 Open Access This article is distributed under the terms of the Creative Commons Attribution 4.0 International License (http://creativecommons.org/licenses/by/4.0/), which permits unrestricted use, distribution, and reproduction in any medium, provided you give appropriate credit to the original author(s) and the source, provide a link to the Creative Commons license, and indicate if changes were made. The Creative Commons Public Domain Dedication waiver (http://creativecommons.org/publicdomain/zero/1.0/) applies to the data made available in this article, unless otherwise stated. 
(Continued from previous page)

Conclusion: Intravenous and subsequent long-term oral TXA produced less blood loss and less swelling and ecchymosis compared with short-term TXA without increasing the risk of complications.

Trial registration: The trial was registered in the Chinese Clinical Trial Registry (ChiCTR-IPR-17012264).

Keywords: Total knee arthroplasty, Tranexamic acid, Blood loss, Swelling,

\section{Background}

Total knee arthroplasty (TKA) is viewed as one of the most successful orthopedic surgeries for most end-stage knee diseases [1]. In recent years, the concept of enhanced recovery after surgery (ERAS) has greatly improved the speed of rehabilitation after total joint arthroplasty. Patients feel more comfortable during the perioperative period and have shorter hospital stays and lower cost [2, 3]. Tranexamic acid (TXA) plays an important role in ERAS due to its antifibrinolytic function [4]. TXA can prevent the activation of plasminogen and delay fibrinolysis and reduce blood loss and the rate of blood transfusion perioperatively [5-7]. Recent studies showed that TXA may be administered intravenously, intra-articularly, or orally [8-11].

Tourniquets can reduce blood loss during operations and provide a better view for surgeons, but the use of a tourniquet may be related to muscle damage, paralysis, severe thigh pain, delayed rehabilitation, and reduced patient satisfaction $[12,13]$. Considering these concerns, not using a tourniquet during TKA surgery can avoid those side effects and promote recovery postoperatively. Similarly, some studies of tourniquet use during TKA showed that avoiding tourniquets can reduce pain and edema from the operation side of the lower limb without increasing blood loss with use of multiple doses of TXA $[14,15]$.

Many guidelines recommend that anticoagulants be used during TKA to prevent venous thromboembolism (VTE), including deep vein thrombosis (DVT) and pulmonary embolism (PE) after TKA $[16,17]$. New oral anticoagulants, such as Rivaroxaban and Apixaban, can effectively reduce the occurrence of DVT and PE, but there are still some side effects when patients take these drugs, including swelling, ecchymosis, or wound complications. These side effects may make patients panic and are disadvantageous to recovery after surgery [18-22].

A large number of studies confirmed that intravenous, intra-articular, or oral use of tranexamic acid can reduce blood loss and be helpful for reducing inflammation and swelling from limb surgery, reducing the occurrence of subcutaneous ecchymosis, but does not increase the incidence of thrombosis $[6,9,14,23-26]$. In our clinical work, we found that during the anticoagulation process (from the day of surgery to POD 14) after joint replacement, most patients may have various degrees of subcutaneous ecchymosis. We considered that subcutaneous ecchymosis may be caused by anticoagulant drugs that can induce hidden blood loss or subcutaneous capillary bleeding. Subcutaneous ecchymosis was one of the main problems indicated by patients during the follow-up visit and was not conducive to early postoperative rehabilitation. Studies have supported that the use of tranexamic acid during hospitalization could reduce the incidence of subcutaneous ecchymosis in patients undergoing arthroplasty, and we wondered whether prolonged use of tranexamic acid postoperatively could enhance patient recovery and reduce the incidence of subcutaneous ecchymosis after discharge. However, in almost all of these previous studies, the use of TXA occurred in the hospital, and there has been no related research about the efficacy and safety of long-term use of oral TXA after TKA. Therefore, we designed a prospective, randomized, double-blind placebo trial conducted in an enhanced recovery setup at our institution to assess the efficacy and safety of extended oral tranexamic acid after primary unilateral total knee arthroplasty with no tourniquet or drain. We hypothesized that, compared with placebo, after total knee arthroplasty, extended oral TXA would reduce blood loss, incidence of subcutaneous ecchymosis and limb swelling with Rivaroxaban to prevent thrombosis post-discharge without increased thromboembolic complications.

\section{Methods \\ Patients}

This study was conducted at the Department of Joint Surgery in West China Hospital, Sichuan University, and registered in the Chinese Clinical Trial Registry (ChiCTRIPR-17012264). The Institutional Review Board (Medical Ethics Committee of West China Hospital, Sichuan University) give permission for our study.

From September 2017 and April 2018, patients with primary osteoarthritis undergoing primary unilateral TKA were screened for enrollment. Perioperative management of surgery was based on a widely recognized multimodal enhanced recovery strategy, including VTE prevention, pain control [27-29], blood loss management [30], and rehabilitation training [31, 32]. The exclusion criteria were secondary osteoarthritis, allergy to this medicine, a history of coexisting diseases that cannot tolerate surgery or general anesthesia, and active cancer. 


\section{Drug delivery and randomization}

All patients were randomized into two groups (Group A: IV and subsequent oral TXA; Group B: IV TXA only) based on a computer-generated randomization list generated using Randomization.com. The randomization was prepared by a statistician who was not involved in this clinical trial. The randomization assignments were placed into sequentially numbered opaque sealed envelopes, which were kept by a certificated research pharmacist. The envelope was opened on the day of operation, and the corresponding drug and placebo were handled by a researcher who was not involved in patient care. The patients, trial participants, anesthesiologists, outcome assessors, and data collectors were blinded to allocation. The placebo (starch tablet) that had the same appearance as oral TXA was provided from a specific department in our hospital. The patients in Group A were given TXA $(20 \mathrm{mg} / \mathrm{kg})$ intravenously $10 \mathrm{~min}$ before the surgery and $3 \mathrm{~h}$ after the operation, and then the patients received 1 g TXA orally from postoperative day (POD) 1 to POD 14. Patients in the Group B received IV TXA $(20 \mathrm{mg} / \mathrm{kg})$ intravenously $10 \mathrm{~min}$ before the surgery and $3 \mathrm{~h}$ after the operation, and then the patients received placebo pills identical in quantity to oral TXA from POD 1 to POD 14. All the operations were performed by a senior doctor.

\section{Surgical procedure and postoperative management}

All patients were under general anesthesia and used a medial para-patellar approach. All patients also received standard analgesia perioperatively [27, 28], including adductor canal block ( $30 \mathrm{ml} 0.33 \%$ ropivacaine) before the operation and periarticular multisite infiltration $(40 \mathrm{ml}$ $0.25 \%$ ropivacaine) before fixing the prosthesis. A tourniquet, intraarticular drainage tube, and pressure dressing were not used in any patients in this study [22, 33]. All of the patients had a doppler ultrasound conducted by experienced ultrasound doctor to diagnose DVT before the operation, at POD 14 and 3 months postoperatively. PEs were detected by clinical symptoms and contrastenhanced chest CT scans if it's necessary.

During hospitalization, all patients received low molecular weight heparin (Clexane, Sanofi-Aventis, France) and a venous pump (the first night after the operation) to prevent VTE. Patients were asked to perform equal length contractions of the femoral quadriceps and ankle pump movements 20 times per minute as soon as they recovered from anesthesia. Rivaroxaban $(10 \mathrm{mg}$, Xarelto, Bayer, Germany) was administered orally once a day for another 10 days after determining no bleeding events occurred.

Based on the guidelines of the Chinese Ministry of Health, an allogeneic transfusion was given if $\mathrm{Hb}$ was < $70 \mathrm{~g} / \mathrm{L}$ in asymptomatic patients or between $70 \mathrm{~g} / \mathrm{L}$ and $100 \mathrm{~g} / \mathrm{L}$ in symptomatic patients (i.e. fatigue, poor appetite, anemia, or myocardial ischemia) in hospital. An attending physician who did not participate in the study made the transfusion decision [34].

\section{Outcome measurements}

Patient's age, sex, American Society of Anesthesiologists (ASA) classification, Caprini score, weight, height, body mass index (BMI) and predicted blood volume (PBV) were collected for comparison. The primary outcomes was total blood loss (TBL), and estimated blood loss was calculated applying the Gross formula [35]:

Total blood loss $=$ PBV x $($ Hct pre-Hct post $) /$ Hct ave

PBV = patient's blood volume

Hct pre $=$ the initial preoperative hematocrit level Hct post $=$ the lowest postoperative hematocrit level during hospitalization or the lowest postoperative hematocrit prior to blood transfusion

Hct ave $=$ the average of Hct pre and Hct post

The PBV was assessed according to the formula from Nadler et al [36]:

PBV $(\mathrm{mL})=\mathrm{k} 1 \times$ height $(\mathrm{m})+\mathrm{k} 2 \mathrm{x}$ weight $(\mathrm{kg})+\mathrm{k} 3$; $\mathrm{k} 1=0: 3669, \mathrm{k} 2=0: 03219$, and $\mathrm{k} 3=0: 6041$ for men; $\mathrm{k} 1=$ $0: 3561, \mathrm{k} 2=0: 03308$, and $\mathrm{k} 3=0: 1833$ for women. If a reinfusion or an allogenic transfusion was conducted, the volume transfused was added when calculating TBL.

The secondary outcomes included the subcutaneous ecchymosis morbidity, area of ecchymosis, patients requiring transfusion, units transfused, and postoperative laboratory values (i.e. hemoglobin, hematocrit, FDP, and D-Dimer). Postoperative knee function, knee circumference, VAS pain score, and length of hospital stay were also assessed as the secondary outcomes. Hemoglobin was measured before the operation and at POD 1, 3, and 14. Based on previous literature and our own experience, the patient's hemoglobin level was minimized on the third day after TKA. We chose POD 3 to measure total blood loss. Two experienced clinicians who did not participate in the study judged the degrees of ecchymosis and swelling, which were consistent with our previous studies [33]. If subcutaneous ecchymosis was found at any part of the surgical limb, the range of ecchymosis was measured as the percentage of body surface area (area of the patient's own palm defined as approximately $1 \%$ of body surface area, referenced in the estimation of burn area by Lund-Browder [37]. Knee circumference was measured as thigh circumference $10-\mathrm{cm}$ proximal to the patellar. If the surgical side was over than the contralateral limb was defined as positive. Limb swelling was measured before operation and on POD 1, 3, and 14 and after 3 months. As for complications, we recorded complications (DVT, infection, and wound secretion), 
30-day mortality, and 90-day readmission. Marsh's Satisfaction Questionnaire was used to investigate patient satisfaction.

\section{Sample-size calculations}

The sample size was calculated on the basis of the difference in the primary outcome, namely, total blood loss. Based on pilot data from 66 patients who received unilateral primary TKA with use of the same fast-track program between March 2016 and November 2016, the mean total blood loss was $978 \mathrm{ml}$ (SD 229). The relevant additional clinical effect of reduced total blood loss based on the added use of oral TXA following its use preoperatively was found to be $164 \mathrm{ml}$ in the historical cohort [38] . Based on these parameters, it was determined that 48 patients were required per group, with an assumed alpha of $5 \%$ and a power of $95 \%$. To allow for loss to follow-up of 20\%, 60 patients were needed for each group. Calculations were performed with $\mathrm{G}^{*}$ Power 3.1.

\section{Statistical analysis}

The mean and standard deviation (SD) were calculated for the quantitative data, and frequencies and percentages were calculated for qualitative data. Before any analyses were performed, the distributions of all variables were tested by the Kolmogorov-Smirnov test. An unpaired Student's t-test was used when the data appear to be normally distributed. Otherwise, the Mann-Whitney $\mathrm{U}$ test was used. The chi-squared or Fisher's exact tests was performed to analyze categorical variables. Significance was set at $p<0.05$. Analyses were performed using SPSS Version 22.0 (IBM Corp., Armonk, New York).

\section{Results \\ Patients}

From September 2017 to April 2018, 210 patients scheduled for primary unilateral TKA were screened for participation in our trial. Ninety patients were excluded, and the remaining 120 patients underwent randomization into two groups: Group A (IV and subsequent oral TXA group, $n=60$ ) and Group B (IV TXA group, $n=60$ ). Two patients in Group B were excluded because of tourniquet application (1 patient) and medication not being prepared in time (1 patient) (Fig. 1). No patient was lost or excluded during follow-up. No significant differences between the two groups were identified with respect to demographic data, operative time, Caprini score, knee function, or preoperative laboratory values (Table 1). The follow-up duration was 3 months after surgery.

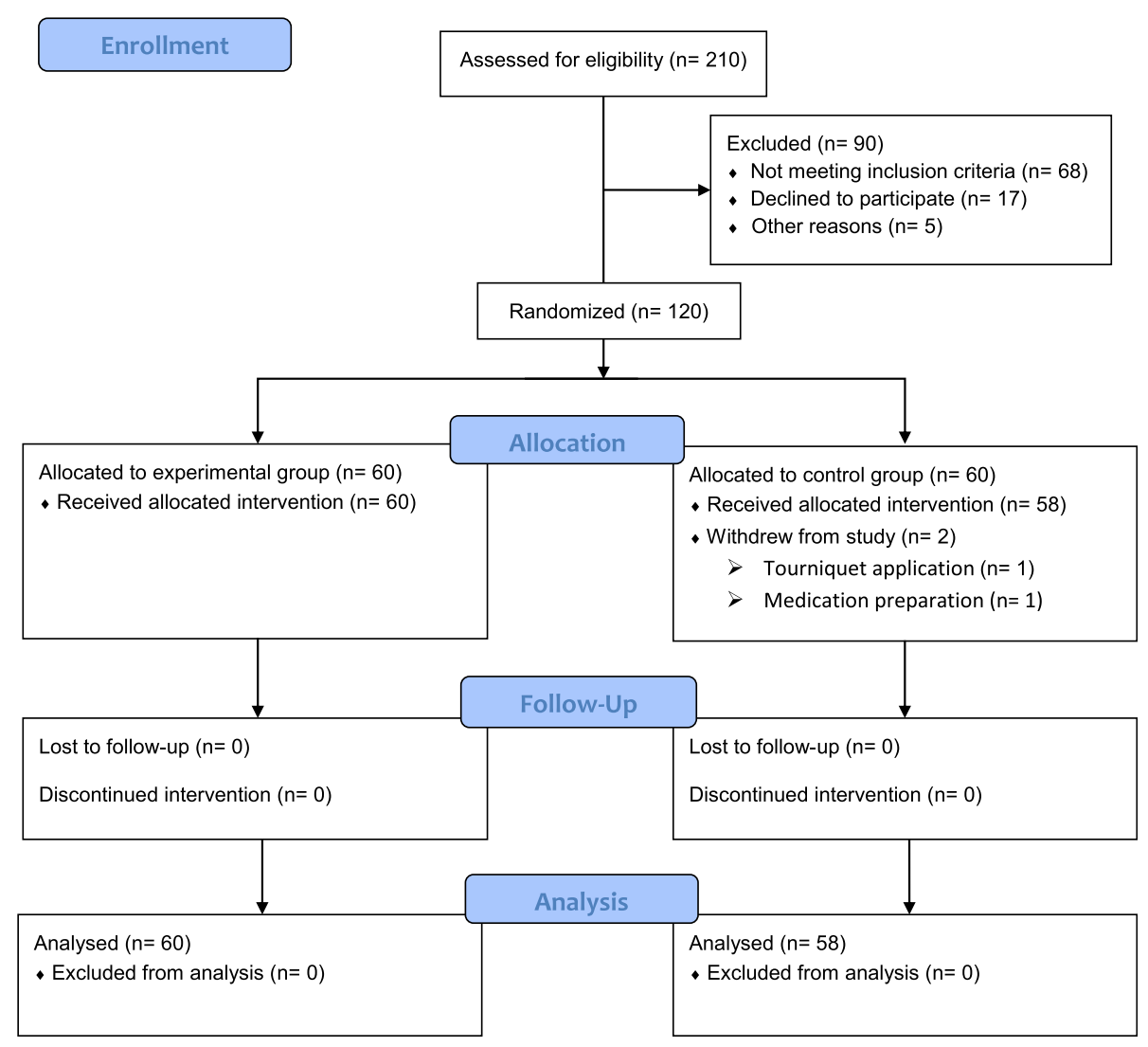

Fig. 1 CONSORT (Consolidated Standards of Reporting Trials) flow diagram 
Table 1 Baseline characteristics and perioperative demographics

\begin{tabular}{|c|c|c|c|}
\hline Variable & Group A $(N=60)$ & Group B $(N=58)$ & $P$ value \\
\hline \multicolumn{4}{|l|}{ Patient characteristics } \\
\hline Age $(\text { year })^{b}$ & $63.0 \pm 13.9$ & $64.1 \pm 9.3$ & 0.62 \\
\hline Gender (male/female) ${ }^{a}$ & $15 / 45$ & $11 / 47$ & 0.43 \\
\hline Height $(m)^{b}$ & $1.5 \pm 0.06$ & $1.6 \pm 0.07$ & 0.07 \\
\hline Weight $(\mathrm{kg})^{\mathrm{b}}$ & $60.9 \pm 10.7$ & $62.3 \pm 10.4$ & 0.46 \\
\hline BMI $\left(\mathrm{kg} / \mathrm{m}^{2}\right)^{\mathrm{b}}$ & $25.7 \pm 5.0$ & $25.5 \pm 3.9$ & 0.79 \\
\hline ASA classification ${ }^{b}$ & $2.1 \pm 0.3$ & $2.1 \pm 0.4$ & 0.53 \\
\hline Operated side $(L / R)^{a}$ & $26 / 34$ & $31 / 27$ & 0.27 \\
\hline $\operatorname{PBV}(L)^{b}$ & $3.5 \pm 0.4$ & $3.6 \pm 0.5$ & 0.19 \\
\hline Caprini scores $^{b}$ & $5.1 \pm 2.5$ & $5.6 \pm 2.6$ & 0.46 \\
\hline \multicolumn{4}{|l|}{ Preoperative laboratory values } \\
\hline Hemoglobin $(g / L)^{b}$ & $130.5 \pm 13.7$ & $128.3 \pm 13.2$ & 0.36 \\
\hline Hematocrit $(\%)^{\mathrm{b}}$ & $39.1 \pm 3.7$ & $38.7 \pm 3.7$ & 0.55 \\
\hline Platelet count $\left(\times 10^{9} / \mathrm{L}\right)^{\mathrm{b}}$ & $182.7 \pm 55.2$ & $179.1 \pm 45.5$ & 0.73 \\
\hline Albumin $(g / L)^{b}$ & $42.0 \pm 6.1$ & $43.0 \pm 3.2$ & 0.28 \\
\hline $\mathrm{FDP}(\mathrm{mg} / \mathrm{L})^{\mathrm{b}}$ & $3.1 \pm 2.5$ & $2.9 \pm 2.4$ & 0.70 \\
\hline D-Dimer $(\mathrm{mg} / \mathrm{L})^{\mathrm{b}}$ & $1.0 \pm 1.4$ & $1.2 \pm 1.4$ & 0.46 \\
\hline PT (s)b & $11.4 \pm 0.7$ & $11.3 \pm 1.0$ & 0.62 \\
\hline \multicolumn{4}{|l|}{ Surgical data } \\
\hline Operative time $(\mathrm{min})^{b}$ & $62.9 \pm 13.1$ & $63.6 \pm 12.4$ & 0.56 \\
\hline \multicolumn{4}{|l|}{ Preoperative knee function } \\
\hline $\mathrm{ROM}\left({ }^{\circ}\right)^{\mathrm{b}}$ & $98.0 \pm 22.4$ & $96.6 \pm 17.4$ & 0.71 \\
\hline KSS clinical score ${ }^{b}$ & $35.8 \pm 14.4$ & $36.2 \pm 15.8$ & 0.89 \\
\hline KSS function score ${ }^{b}$ & $42.4 \pm 11.6$ & $41.2 \pm 10.1$ & 0.57 \\
\hline Knee circumference $(\mathrm{cm})^{\mathrm{b}}$ & $41.1 \pm 4.0$ & $41.4 \pm 3.5$ & 0.58 \\
\hline VAS pain score ${ }^{b}$ & $5.4 \pm 1.4$ & $5.8 \pm 1.5$ & 0.10 \\
\hline
\end{tabular}

${ }^{a}$ The values are given as the number of patients

${ }^{\mathrm{b}}$ The values are presented as the mean and the standard deviation

\section{Primary outcome}

The total blood loss (primary outcome) was $671.7 \pm$ $352.7 \mathrm{~mL}$ in Group A and $915.8 \pm 243.4 \mathrm{~mL}$ in Group B, $(p=0.001)$, and there was a significant difference between the groups (Table 2).

\section{Secondary outcomes}

\section{Subcutaneous ecchymosis}

During the period of follow-up, the morbidity of ecchymosis was higher in Group B (38 patients) than in Group A (7 patients), $P=0.001$. The area of ecchymosis of the operative side limb in Group A was smaller than Group B (1.6\% of the body surface area in group A vs $3.0 \%$ in group $\mathrm{B}, P=0.001$ ) (Table 2 ).

\section{Postoperative laboratory values}

No difference between the two groups was identified in $\mathrm{Hb}$ level or hematocrit on POD 1 or POD 14, but on POD 3, Hb and hematocrit in Group A were higher than in Group $B(P=0.001$ and $P=0.001$, respectively). The levels of FDP and D-Dimer were lower in Group A, and at the POD 1 (FDP: 13.7 vs 24.9, D-Dimmer:4.6 vs 8.4) and POD 3 (FDP: 6.9 vs 12.0, D-Dimmer:1.5 vs 3.3), there were significant differences $(P<0.05)$, but on POD 14, FDP and D-Dimmer were similar between the groups (Table 2).

\section{Postoperative knee function and knee circumference}

Knee ROM and KSS score were similar among the two groups during the 3-month follow-up. Similarly, the postoperative VAS was not significantly different between the groups at any follow-up point (Table 2).

The swelling of the lower limb in Group A was more mild than in Group B on POD 3 and POD 14. The circumference of the knee was $43.1 \mathrm{~cm}$ vs $46.1 \mathrm{~cm}$ (POD 3, $P=0.001)$ and $41.4 \mathrm{~cm}$ vs $44.9 \mathrm{~cm}$ (POD $14, P=0.001$ ) for Group A vs Group B, respectively but there was no 
Table 2 Primary and secondary outcomes regarding laboratory values and clinical outcomes after surgery

\begin{tabular}{|c|c|c|c|c|c|c|c|}
\hline & \\
\hline Variable & Group A & Group B & $P$ value & Variable & Group A & Group B & $P$ value \\
\hline \multicolumn{4}{|l|}{ Primary outcomes } & POD 1 & $3.8 \pm 1.5$ & $4.2 \pm 2.0$ & 0.26 \\
\hline Total blood loss $(\mathrm{mL})^{\mathrm{b}}$ & $671.7 \pm 352.7$ & $915.8 \pm 243.4$ & 0.001 & POD 3 & $2.7 \pm 0.8$ & $2.9 \pm 0.7$ & 0.11 \\
\hline \multicolumn{4}{|l|}{ Secondary outcomes } & POD 14 & $2.2 \pm 1.0$ & $2.0 \pm 0.8$ & 0.32 \\
\hline \multicolumn{4}{|l|}{ Postoperative transfusion } & $\mathrm{PO} 3 \mathrm{M}$ & $0.7 \pm 0.9$ & $0.6 \pm 0.8$ & 0.35 \\
\hline Patients requiring transfusion & $2(3.33 \%)$ & $2(3.45 \%)$ & 0.44 & Hospital stay (day) ${ }^{\text {b }}$ & $3.7 \pm 1.2$ & $4.0 \pm 0.9$ & 0.15 \\
\hline Units transfused (IU) & 3.5 & 4 & NA & & & & \\
\hline \multicolumn{4}{|l|}{ Postop. laboratory values } & \multirow{2}{*}{\multicolumn{4}{|c|}{$\begin{array}{l}\text { difference between the two groups on POD } 1 \text { or the } 3 \text { - } \\
\text { month follow-up (Table 2). }\end{array}$}} \\
\hline \multicolumn{4}{|l|}{ Hemoglobin $(g / L)^{b}$} & & & & \\
\hline POD 1 & $115.3 \pm 13.9$ & $117.1 \pm 11.6$ & 0.55 & & & & \\
\hline POD 3 & $106.0 \pm 10.9$ & $99.7 \pm 8.4$ & 0.001 & \multirow{8}{*}{\multicolumn{4}{|c|}{$\begin{array}{l}\text { Length of hospital stay and patient satisfaction } \\
\text { The length of hospital stay was } 3.7 \text { days in Group A VS } \\
4.0 \text { days in Group B, } P=0.15 \text { (Table } 2 \text { ). Patients in Group } \\
\text { A had better satisfaction as there were } 52 \text { patients } \\
(86.7 \%) \text { who were satisfied with the surgery, but only } 46 \\
\text { patients ( } 70.3 \% \text { ) in Group B were satisfied, but here was } \\
\text { no difference between the two groups. The main reason } \\
\text { that made patients feel uncomfortable were pain, swell- } \\
\text { ing of the limb and ecchymosis (Table } 3 \text { ). }\end{array}$}} \\
\hline POD 14 & $123.8 \pm 10.3$ & $121.3 \pm 8.1$ & 0.13 & & & & \\
\hline Hematocrit $(\%)^{b}$ & & & & & & & \\
\hline POD 1 & $35.1 \pm 4.2$ & $35.7 \pm 3.2$ & 0.43 & & & & \\
\hline POD 3 & $32.3 \pm 2.9$ & $30.0 \pm 2.5$ & 0.001 & & & & \\
\hline POD 14 & $37.0 \pm 4.5$ & $36.4 \pm 4.6$ & 0.45 & & & & \\
\hline \multicolumn{4}{|l|}{$\mathrm{FDP}(\mathrm{mg} / \mathrm{L})^{\mathrm{b}}$} & & & & \\
\hline POD 1 & $13.7 \pm 7.8$ & $24.9 \pm 11.3$ & 0.001 & & & & \\
\hline POD 3 & $6.9 \pm 3.4$ & $12.0 \pm 10.0$ & 0.001 & & & & \\
\hline POD 14 & $4.4 \pm 2.5$ & $5.2 \pm 2.4$ & 0.083 & \multirow{6}{*}{\multicolumn{4}{|c|}{$\begin{array}{l}\text { Transfusion rate } \\
\text { Four patients received allogeneic blood transfusion due } \\
\text { to a postoperative } \mathrm{Hb} \text { of }<70 \mathrm{~g} / \mathrm{L} \text { and had symptoms in- } \\
\text { dicative of anemia. Two were patients }(3.3 \%, 3.5 \mathrm{U}) \text { in } \\
\text { Group A and } 2(3.5 \%, 4.0 \mathrm{U}) \text { were in Group } \mathrm{B} \text {, and there } \\
\text { was no significant difference between the two groups } \\
\text { (Table } 2) \text {. }\end{array}$}} \\
\hline D-Dimer $(\mathrm{mg} / \mathrm{L})^{\mathrm{b}}$ & & & & & & & \\
\hline POD 1 & $4.6 \pm 2.2$ & $8.4 \pm 8.0$ & 0.001 & & & & \\
\hline POD 3 & $1.5 \pm 1.1$ & $3.3 \pm 2.1$ & 0.001 & & & & \\
\hline POD 14 & $1.2 \pm 0.9$ & $1.3 \pm 0.5$ & 0.22 & & & & \\
\hline \multicolumn{4}{|l|}{ Postop. knee function } & & & & \\
\hline \multicolumn{4}{|l|}{$\mathrm{ROM}\left({ }^{\circ}\right)^{\mathrm{b}}$} & \multicolumn{4}{|c|}{ Table 3 Other outcomes including adverse events } \\
\hline POD 1 & $99.7 \pm 11.8$ & $100.1 \pm 11.7$ & 0.58 & & & & $P$ value \\
\hline POD 3 & $108.1 \pm 4.9$ & $107.4 \pm 5.2$ & 0.44 & Ecchymeses & 7 & 38 & 0001 \\
\hline POD 14 & $110.9 \pm 8.9$ & $108.2 \pm 9.4$ & 0.11 & Area ferchymeses(o/ b & 16 & & 0.001 \\
\hline $\mathrm{PO} 3 \mathrm{M}$ & $114.0 \pm 7.0$ & $113.7 \pm 9.5$ & 0.82 & & & $3.0 \pm 1.3$ & 0.001 \\
\hline KSS clinical score ${ }^{b}$ & & & & Symptomatic DVI & 0 & 0 & NA \\
\hline POD 3 & $48.2 \pm 8.9$ & $45.6 \pm 8.5$ & 0.32 & Asymptomatic DVT & 5 & 3 & 0.50 \\
\hline POD 14 & $77.3 \pm 6.4$ & $75.2 \pm 9.1$ & 15 & Superficial infection & 0 & 0 & 1.00 \\
\hline $\mathrm{PO} 3 \mathrm{M}$ & $82.8 \pm 5.5$ & $82.5 \pm 4.3$ & 78 & Deep infection & 0 & 0 & NA \\
\hline KSS function score ${ }^{b}$ & & & & Hematoma & 0 & 0 & NA \\
\hline POD 3 & $44.5 \pm 10.6$ & $43.1 \pm 10.2$ & 0 & Wound secretion & 2 & 1 & 0.58 \\
\hline POD 14 & $68.6 \pm 8.1$ & $695+84$ & 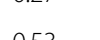 & 30-day mortality & 0 & 0 & NA \\
\hline PO $3 \mathrm{M}$ & $75.5 \pm 5.6$ & $767+53$ & & 90-day readmission & 0 & 0 & NA \\
\hline Knee circumference $(\mathrm{cm})^{\mathrm{b}}$ & & & & Satisfaction level & & & \\
\hline POD 1 & & & & Extremely satisfied & 21 & 18 & 0.88 \\
\hline POD 3 & & & & Very satisfied & 19 & 17 & \\
\hline POD 14 & $45.1 \pm 1.9$ & $46.1 \pm 3.7$ & 0.001 & Somewhat satisfied & 12 & 11 & \\
\hline $\mathrm{PO} 3 \mathrm{M}$ & 41 & 4 & 0 & Neither satisfied nor dissatisfied & 7 & 10 & \\
\hline VAS pa & & & 0.20 & Somewhat dissatisfied & 1 & 2 & \\
\hline & & & & Very dissatisfied & 0 & 0 & \\
\hline
\end{tabular}

Table 2 Primary and secondary outcomes regarding laboratory values and clinical outcomes after surgery (Continued)

difference between the two groups on POD 1 or the 3-

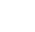

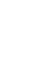




\section{Complications}

DVT morbidity, wound secretion and infection did not differ significantly between the two groups, and there were no mortality or readmission events during the follow-up period (Table 3).

\section{Discussion}

Good blood conservation during the perioperative period can reduce blood loss and transfusion and decrease anemia, and patients who have higher levels of hemoglobin display better physical abilities and executive abilities during rehabilitation training [8, 30, 39-41]. Many studies including meta-analyses have proven that corrected anemia can reduce mortality after surgery [42-44]. Blood conservation strategies are one of the core components of the ERAS strategy for TKA, and TXA makes this strategy a reality.

TXA has been widely used to reduce blood loss and transfusion following TKA, especially in ERAS. Increasing numbers of studies have supported this fact $[2,15$, 40, 43, 45-48]. In China, more than two hundred thousand primary TKAs are conducted each year. Considering the aging population and longer life expectancy, this number of TKAs will increase dramatically over time. TXA is useful for reducing swelling and inflammatory reactions after total joint arthroplasty $[49,50]$. Although previous studies showed that hyperfibrinolysis continued for approximately 6-18 h after the operation, anticoagulants, such as low molecular heparin or rivaroxaban, might cause new bleeding. Fibrinolysis could persist at a low level, which is why some studies showed that prolonged use of TXA or multiple-dose drugs can further reduce blood loss and restrain postoperative fibrinolysis better than a single dose [23, 51-53]. We believe that prolonged use of TXA has more benefits for patients with total joint arthroplasty.

This study is the first study of long-term use of TXA after TKA. The results of our study show that, in the group with long-term use of TXA after the surgery (Group A), patients had lower total blood loss than Group B and patients in Group A had a higher hemoglobin than Group B on POD 3, that means when we prolonged the uses of TXA, it could reduce the blood lose from POD 1 to POD 3. The blood coagulation level as measured by fibrinolysis (D-Dimer) was lower in Group A than in Group B on POD 1 and POD 3. Patients in Group A had less ecchymosis morbidity, smaller ecchymosis area, and less swelling than Group B. Those results confirmed from another aspect that prolonged the use of tranexamic acid was helpful in inhibiting fibrinolysis and reducing the morbidity of swelling and subcutaneous ecchymosis of the lower limb after TKA. When we prolonged the use TXA after surgery, the total blood loss was comparable at two or three times the short-term use on the operation day and after the surgery [34, 54]. However, our scheme is more acceptable to patients because they did not need to take oral or intravenous TXA frequently on the operation day after general anesthesia.

The guidelines for the prevention of venous thromboembolism after orthopedic surgery in China suggest that, after total knee arthroplasty, we should use anticoagulants for at least 10 to 14 days $[55,56]$. In the ERAS strategy, surgeons tried to find a balance of bleeding, hemostasis, anticoagulation and antiplasmin. In our institution, we attempt use TXA to achieve this balance. To date, our department has published dozens of papers and proved this conclusion $[9,14,15,26,28,30,46,54$, 57]. Patients are discharged fewer than 3 days after total knee arthroplasty, but they should take oral anticoagulants, such as rivaroxaban, for more than 10 days at home to prevent VTE. There are few community health service institutions in China, and doctors there cannot supervise patient follow-up. When patients feel uncomfortable or anxious about the side effects of drugs, such as subcutaneous ecchymosis or swelling, they might travel hundreds of miles to meet with their surgeons. The results of our study proved that long-term, oral TXA after discharge from the hospital decreases ecchymosis and swelling caused by anticoagulants and made patients feel more comfortable and less anxious.

Although this study was carefully designed, there were still several limitations. First, the study population was small. For the incidence of ecchymosis and swelling, we believe that a larger sample size would be better powered to detect differences between the two groups, but the sample size calculations showed that our small sample was sufficient. Second, peak blood concentration occurs at approximately $3 \mathrm{~h}$, and the half-life of oral TXA is approximately $2 \mathrm{~h}$, but rivaroxaban reaches a peak $2 \mathrm{~h}$ after oral administration with a half-life of 4-6h. Oral TXA might be not match the effect of rivaroxaban, and we plan to design another study and increase the frequency of oral TXA to obtain better results. Third, the 3-month follow-up might have concealed a different long-term safety profile for oral TXA. Forth, there were multiple secondary outcomes without correction that will be considered in future research. However, the halflife of TXA is short, and a 3-month follow-up period should have been adequate for observing attributable side effects or important early adverse reactions.

\section{Conclusion}

This prospective, randomized, controlled trial of total knee arthroplasty using a fast-track protocol with no tourniquet and postoperative drain demonstrated that intravenous and subsequent long-term oral tranexamic 
acid provided less blood loss, less swelling, and less ecchymosis compared with short term TXA use without increasing the risk of complications.

\author{
Abbreviations \\ ASA: The American Society of Anesthesiologists; ERAS: Enhanced recovery \\ after surgery; FDP: Fibrin degradation products; IA: Intra-articularly; \\ IV: Intravenous; KSS: Knee society score; PE: Pulmonary embolism; \\ ROM: Range of motion; TKA: Total knee arthroplasty; TXA: Tranexamic acid; \\ VTE: Venous thromboembolism
}

\section{Acknowledgements}

This study adheres to CONSORT guidelines. We are thankful for the support of the nursing staffs from the Department of Orthopedic Surgery, West China Hospital and the patients enrolled in this study.

\section{Authors' contributions}

HYW and LW performed the data collection and analysis and participated in manuscript writing. HYW and ZYL performed the database setup and statistical analysis. HYW, ZYL, FXP and ZKZ performed the operations. HYW $D W, X T$, and LW participated in the study design and coordination and helped to draft the manuscript. All the authors have read and approved the final manuscript.

\section{Funding}

This research was funded by the China Health Ministry Program (201302007), who is not involved in study design, data collection, analysis and interpretation or manuscript preparation.

\section{Availability of data and materials}

The datasets used and analyzed during the current study are available from the corresponding author on reasonable request.

\section{Ethics approval and consent to participate}

This study was approved by The Institutional Review Board (Medical Ethics Committee of West China Hospital, Sichuan University) and written informed consent to participate was obtained from all of the individual participants included in the study.

\section{Consent for publication}

Not applicable.

\section{Competing interests}

The authors declare that they have no competing interests.

\section{Author details}

'Department of Orthopedics, West China Hospital/West China School of Medicine, Sichuan University, 37\# Wuhou Guoxue road, Chengdu 610041 People's Republic of China. ${ }^{2}$ State Key Laboratory of Oral Diseases \& National Clinical Research Center for Oral Diseases, Sichuan University, Chengdu 610041, People's Republic of China. ${ }^{3}$ Department of Cariology and Endodontics, West China Hospital of Stomatology, Sichuan University, Chengdu 610041, People's Republic of China.

\section{Received: 29 October 2018 Accepted: 10 October 2019}

Published online: 25 October 2019

\section{References}

1. Indelli PF, Risitano S, Hall KE, Leonardi E, Migliore E. Effect of polyethylene conformity on total knee arthroplasty early clinical outcomes. Knee Surg Sports Traumatol Arthrosc. 2019;27(4):1028-34

2. Zhang S, Huang Q, Xie J, Xu B, Cao G, Pei F. Factors influencing postoperative length of stay in an enhanced recovery after surgery program for primary total knee arthroplasty. J Orthop Surg Res. 2018;13(1):29.

3. Zhu S, Qian W, Jiang C, Ye C, Chen X. Enhanced recovery after surgery for hip and knee arthroplasty: a systematic review and meta-analysis. Postgrad Med J. 2017:93(1106):736-42.

4. Alshryda S, Sukeik M, Sarda P, Blenkinsopp J, Haddad FS, Mason JM. A systematic review and meta-analysis of the topical administration of tranexamic acid in total hip and knee replacement. Bone Joint J. 2014;96b(8):1005-15.
5. Astedt B. Clinical pharmacology of tranexamic acid. Scand J Gastroenterol Suppl. 1987;137:22-5.

6. Chang CH, Chang Y, Chen DW, Ueng SW, Lee MS. Topical tranexamic acid reduces blood loss and transfusion rates associated with primary total hip arthroplasty. Clin Orthop Relat Res. 2014;472(5):1552-7.

7. Gandhi R, Evans HM, Mahomed SR, Mahomed NN. Tranexamic acid and the reduction of blood loss in total knee and hip arthroplasty: a meta-analysis. BMC Res Notes. 2013;6:184

8. Alipour M, Tabari M, Keramati M, Zarmehri AM, Makhmalbaf H. Effectiveness of oral Tranexamic acid administration on blood loss after knee artroplasty: a randomized clinical trial. Transfus Apher Sci. 2013;49(3):574-7.

9. Cao G, Huang Z, Xie J, Huang Q, Xu B, Zhang S, Pei F. The effect of oral versus intravenous tranexamic acid in reducing blood loss after primary total hip arthroplasty: a randomized clinical trial. Thromb Res. 2018;164:48-53.

10. Guo P, He Z, Wang Y, Gao F, Sun W, Guo W, Li Z, Cheng L. Efficacy and safety of oral tranexamic acid in total knee arthroplasty: a systematic review and meta-analysis. Medicine (Baltimore). 2018;97(18):e0587.

11. Jansen JA, Lameijer JRC, Snoeker BAM. Combined intravenous, topical and oral tranexamic acid administration in total knee replacement: evaluation of safety in patients with previous thromboembolism and effect on hemoglobin level and transfusion rate. Knee. 2017;24(5):1206-12.

12. Huang ZY, Pei FX, Ma J, Yang J, Zhou ZK, Kang PD, Shen B. Comparison of three different tourniquet application strategies for minimally invasive total knee arthroplasty: a prospective non-randomized clinical trial. Arch Orthop Trauma Surg. 2014;134(4):561-70.

13. Alexandersson M, Wang EY, Eriksson S. A small difference in recovery between total knee arthroplasty with and without tourniquet use the first 3 months after surgery: a randomized controlled study. Knee Surg Sports Traumatol Arthrosc. 2019;27(4):1035-42.

14. Cao G, Xie J, Huang Z, Huang Q, Chen G, Lei Y, Xu H, Pei F. Efficacy and safety of multiple boluses of oral versus intravenous tranexamic acid at reducing blood loss after primary total knee arthroplasty without a tourniquet: a prospective randomized clinical trial. Thromb Res. 2018;171: 68-73.

15. Wang D, Wang HY, Cao C, Li LL, Meng WK, Pei FX, Li DH, Zhou ZK. Tranexamic acid in primary total knee arthroplasty without tourniquet: a randomized, controlled trial of oral versus intravenous versus topical administration. Sci Rep. 2018:8(1):13579.

16. Mont MA, Jacobs JJ. AAOS clinical practice guideline: preventing venous thromboembolic disease in patients undergoing elective hip and knee arthroplasty. J Am Acad Orthop Surg. 2011;19(12):777-8.

17. Gharaibeh L, Albsoul-Younes A, Younes N. Evaluation of VTE prophylaxis in an educational hospital: comparison between the institutional guideline (Caprini 2006) and the ACCP guideline (ninth edition). Clin Appl Thromb Hemost. 2016;22(7):627-32

18. Beyer-Westendorf J, Forster K, Pannach S, Ebertz F, Gelbricht V, Thieme C, Michalski F, Kohler C, Werth S, Sahin K, et al. Rates, management, and outcome of rivaroxaban bleeding in daily care: results from the Dresden NOAC registry. Blood. 2014;124(6):955-62.

19. Egger F, Targa F, Unterholzner I, Grant RP, Herrmann M, Wiedermann CJ. Medication error when switching from warfarin to rivaroxaban leading to spontaneous large ecchymosis of the abdominal and Chest Wall. Clin Pract. 2016:6(3):873.

20. Sherwood MW, Nessel CC, Hellkamp AS, Mahaffey KW, Piccini JP, Suh $E Y$, Becker RC, Singer DE, Halperin JL, Hankey GJ, et al. Gastrointestinal bleeding in patients with atrial fibrillation treated with rivaroxaban or warfarin: ROCKET AF trial. J Am Coll Cardiol. 2015; 66(21):2271-81

21. Wang JW, Chen B, Lin PC, Yen SH, Huang CC, Kuo FC. The efficacy of combined use of rivaroxaban and Tranexamic acid on blood conservation in minimally invasive Total knee Arthroplasty a double-blind randomized. Controlled Trial J Arthroplasty. 2017;32(3):801-6.

22. Xie J, Ma J, Huang Q, Yue C, Pei F. Comparison of enoxaparin and rivaroxaban in balance of anti-fibrinolysis and anticoagulation following primary Total knee replacement: a pilot study. Med Sci Monit. 2017;23:704-11.

23. Cao G, Huang Q, Huang Z, Zhang S, Luo Z, Lei Y, Zhou Z, Pei F. The efficacy and safety of multiple-dose oral tranexamic acid on blood loss following total hip arthroplasty: a randomized controlled trial. Int Orthop. 2019:43(2): 299-305.

24. Craik JD, Ei Shafie SA, Kidd AG, Twyman RS. Can local administration of tranexamic acid during total knee arthroplasty reduce blood loss and 
transfusion requirements in the absence of surgical drains? Eur J Orthop Surg Traumatol. 2014;24(3):379-84.

25. Li GL, Li YM. Oral tranexamic acid can reduce blood loss after total knee and hip arthroplasty: a meta-analysis. Int J Surg. 2017:46:27-36.

26. Luo ZY, Wang D, Meng WK, Wang HY, Pan H, Pei FX, Zhou ZK. Oral tranexamic acid is equivalent to topical tranexamic acid without drainage in primary total hip arthroplasty: a double-blind randomized clinical trial. Thromb Res. 2018;167:1-5.

27. Lei YT, Xu B, Xie XW, Xie JW, Huang Q, Pei FX. The efficacy and safety of two low-dose peri-operative dexamethasone on pain and recovery following total hip arthroplasty: a randomized controlled trial. Int Orthop. 2018;42(3):499-505.

28. Li D, Yang Z, Xie X, Zhao J, Kang P. Adductor canal block provides better performance after total knee arthroplasty compared with femoral nerve block: a systematic review and meta-analysis. Int Orthop. 2016;40(5):925-33.

29. Xu B, Ma J, Huang Q, Huang ZY, Zhang SY, Pei FX. Two doses of low-dose perioperative dexamethasone improve the clinical outcome after total knee arthroplasty: a randomized controlled study. Knee Surg Sports Traumatol Arthrosc. 2018:26(5):1549-56.

30. Ma J, Huang Z, Shen B, Pei F. Blood management of staged bilateral total knee arthroplasty in a single hospitalization period. J Orthop Surg Res. 2014; 9:116

31. Wang D, Yang Y, Li Q, Tang SL, Zeng WN, Xu J, Xie TH, Pei FX, Yang L, Li LL, et al. Adductor canal block versus femoral nerve block for total knee arthroplasty: a meta-analysis of randomized controlled trials. Sci Rep. 2017;7: 40721.

32. Zeng WN, Zhou K, Zhou ZK, Shen B, Yang J, Kang PD, Pei FX. Comparison between drainage and non-drainage after total hip arthroplasty in Chinese subjects. Orthop Surg. 2014;6(1):28-32

33. Wang D, Xu J, Zeng WN, Zhou K, Xie TH, Chen Z, Yu HD, Li JL, Zhou ZK, Pei FX. Closed suction drainage is not associated with faster recovery after Total knee Arthroplasty: a prospective randomized controlled study of 80 patients. Orthop Surg. 2016;8(2):226-33.

34. Wang D, Wang HY, Luo ZY, Pei FX, Zhou ZK, Zeng WN. Finding the optimal regimen for Oral Tranexamic acid Administration in Primary Total hip Arthroplasty: a randomized controlled trial. J Bone Joint Surg Am. 2019; 101(5):438-45

35. Gross JB. Estimating allowable blood loss: corrected for dilution. Anesthesiology. 1983;58(3):277-80.

36. Nadler SB, Hidalgo JH, Bloch T. Prediction of blood volume in normal human adults. Surgery. 1962;51(2):224-32.

37. Williams JF, King BT, Aden JK, Serio-Melvin M, Chung KK, Fenrich CA, Salinas J, Renz EM, Wolf SE, Blackbourne LH, et al. Comparison of traditional burn wound mapping with a computerized program. J Burn Care Res. 2013;34(1): e29-35.

38. Wang D, Wang HY, Luo ZY, Meng WK, Pei FX, Li Q, Zhou ZK, Zeng WN Blood-conserving efficacy of multiple doses of oral tranexamic acid associated with an enhanced-recovery programme in primary total knee arthroplasty:a randomized controlled trial. Bone Joint J. 2018;100-B(8): 1025-32.

39. Lee QJ, Ching WY, Wong YC. Blood sparing efficacy of Oral Tranexamic acid in primary Total knee Arthroplasty: a randomized controlled trial. Knee Surg Relat Res. 2017;29(1):57-62

40. Melvin JS, Stryker LS, Sierra RJ. Tranexamic acid in hip and knee Arthroplasty. J Am Acad Orthop Surg. 2015;23(12):732-40.

41. Tuttle JR, Ritterman SA, Cassidy DB, Anazonwu WA, Froehlich JA, Rubin LE. Cost benefit analysis of topical tranexamic acid in primary total hip and knee arthroplasty. J Arthroplast. 2014;29(8):1512-5.

42. Petersen PB, Kehlet $H$, Jorgensen CC. Myocardial infarction following fasttrack total hip and knee arthroplasty-incidence, time course, and risk factors: a prospective cohort study of 24,862 procedures. Acta Orthop. 2018:1-7.

43. Zhang S, Huang Q, Xu B, Ma J, Cao G, Pei F. Effectiveness and safety of an optimized blood management program in total hip and knee arthroplasty: a large, single-center, retrospective study. Medicine (Baltimore). 2018;97(1): e9429.

44. Chamieh JS, Tamim HM, Masrouha KZ, Saghieh SS, Al-Taki MM. The Association of Anemia and its Severity with cardiac outcomes and mortality after Total knee Arthroplasty in noncardiac patients. J Arthroplast. 2016; 31(4):766-70.

45. Yuan X, Li B, Wang Q, Zhang X. Comparison of 3 routes of Administration of Tranexamic Acid on primary unilateral Total knee
Arthroplasty: a prospective, randomized, Controlled Study. J Arthroplasty. 2017;32(9):2738-43.

46. Yue C, Kang P, Yang P, Xie J, Pei F. Topical application of tranexamic acid in primary total hip arthroplasty: a randomized double-blind controlled trial. J Arthroplast. 2014;29(12):2452-6.

47. Zhang LK, Ma JX, Kuang MJ, Zhao J, Wang Y, Lu B, Sun L, Ma XL. Comparison of oral versus intravenous application of tranexamic acid in total knee and hip arthroplasty: a systematic review and meta-analysis. Int J Surg. 2017:45:77-84

48. Zhao H, Xiang M, Xia Y, Shi X, Pei FX, Kang P. Efficacy of oral tranexamic acid on blood loss in primary total hip arthroplasty using a direct anterior approach: a prospective randomized controlled trial. Int Orthop. 2018;42(11): 2535-42.

49. Xie J, Ma J, Yao H, Yue C, Pei F. Multiple boluses of intravenous Tranexamic acid to reduce hidden blood loss after primary Total knee Arthroplasty without tourniquet: a randomized clinical trial. J Arthroplast. 2016;31(11) 2458-64.

50. Xie J, Hu Q, Ma J, Huang Q, Pei F. Multiple boluses of intravenous tranexamic acid to reduce hidden blood loss and the inflammatory response following enhanced-recovery primary total hip arthroplasty: a randomised clinical trial. Bone Joint J. 2017;99-b(11):1442-9.

51. Perreault RE, Fournier CA, Mattingly DA, Junghans RP, Talmo CT. Oral Tranexamic acid reduces transfusions in Total knee Arthroplasty. J Arthroplast. 2017:32(10):2990-4.

52. Wang D, Luo ZY, Yu ZP, Liu LX, Chen C, Meng WK, Yu QP, Pei FX, Zhou ZK, Zeng WN. The antifibrinolytic and anti-inflammatory effects of multiple doses of oral tranexamic acid in total knee arthroplasty patients: a randomized controlled trial. J Thromb Haemost. 2018;16(12):2442-53.

53. Wang D, Yang Y, He C, Luo ZY, Pei FX, Li Q, Zhou ZK, Zeng WN. Effect of multiple doses of Oral Tranexamic acid on Haemostasis and inflammatory reaction in Total hip Arthroplasty: a randomized controlled trial. Thromb Haemost. 2019;119(1):92-103.

54. Wang D, Zhu H, Meng WK, Wang HY, Luo ZY, Pei FX, Li Q, Zhou ZK. Comparison of oral versus intra-articular tranexamic acid in enhancedrecovery primary total knee arthroplasty without tourniquet application: a randomized controlled trial. BMC Musculoskelet Disord. 2018;19(1):85.

55. Falck-Ytter Y, Francis CW, Johanson NA, Curley C, Dahl OE, Schulman S, Ortel TL, Pauker SG, Colwell CW Jr. Prevention of VTE in orthopedic surgery patients: antithrombotic therapy and prevention of thrombosis, 9th ed: American College of Chest Physicians Evidence-Based Clinical Practice Guidelines. Chest. 2012;141(2 Suppl):e278S-325S.

56. Geerts WH, Bergqvist D, Pineo GF, Heit JA, Samama CM, Lassen MR, Colwell CW. Prevention of venous thromboembolism: American College of Chest Physicians Evidence-Based Clinical Practice Guidelines (8th Edition). Chest. 2008;133(6 Suppl):381s-453s.

57. Wang $\mathrm{H}$, Shen $\mathrm{B}$, Zeng Y. Comparison of topical versus intravenous tranexamic acid in primary total knee arthroplasty: a meta-analysis of randomized controlled and prospective cohort trials. Knee. 2014;21(6):987-93.

\section{Publisher's Note}

Springer Nature remains neutral with regard to jurisdictional claims in published maps and institutional affiliations.

Ready to submit your research? Choose BMC and benefit from:

- fast, convenient online submission

- thorough peer review by experienced researchers in your field

- rapid publication on acceptance

- support for research data, including large and complex data types

- gold Open Access which fosters wider collaboration and increased citations

- maximum visibility for your research: over $100 \mathrm{M}$ website views per year

At $\mathrm{BMC}$, research is always in progress.

Learn more biomedcentral.com/submissions 